\title{
Influenza vaccination among children with idiopathic nephrotic syndrome: an investigation of practices
}

\author{
Roman Klifa ${ }^{1 *}$ (D), Julie Toubiana ${ }^{2}$, Alizée Michel ${ }^{1}$, Nathalie Biebuyck', Marina Charbit', Laurence Heidet ${ }^{1}$, \\ Saoussen Krid ${ }^{1}$, Pauline Krug ${ }^{1}$, Rémi Salomon ${ }^{1}$ and Olivia Boyer ${ }^{1}$
}

\begin{abstract}
Background: Annual influenza vaccination is recommended for all children with idiopathic nephrotic syndrome (INS) in France. Consequently, the Social Security automatically sends prescriptions to all patients suffering from a chronic disease. The aim of this study was to evaluate the follow-up to these recommendations.

Methods: We conducted a monocentric retrospective investigation of practices. We included all children with steroid-sensitive INS in remission who attended our clinics from January 1st 2015 to January 1st 2017, resided in France and had a valid phone number. Data were collected from May 2017 to June 2017 through a phone interview and review of clinical charts.

Results: 75 patients met the inclusion criteria. The parents of 57 children could be reached by phone and agreed to participate to the survey. 35/57 (61.4\%) declared having received a prescription during the 2016-2017 campaign. Only 14 children (24.6\%) were vaccinated. 17/43 (39.5\%) parents of unvaccinated children had concerns about the safety of the vaccine, 16/43 (37.2\%) were not aware of the recommendations, 5/43 (11.6\%) had been recommended by their physician not to vaccinate their child, $3 / 43$ (7\%) forgot to have them vaccinated and 2/43 (4.6\%) reported no reason. 13/43 (30\%) unvaccinated children presented a relapse during the flu season - 2/13 during an influenza-like illness whereas 1/14 (7\%) immunized children presented a relapse during the six months of post-vaccination follow-up. Relapse rates were not increased in vaccinated children compared to unvaccinated children $(p=0.15)$, nor in the 6 months following vaccination compared to the 6 months prior $(1 / 14$ vs $5 / 14, p=0.20)$.
\end{abstract}

Conclusions: 1$)<2 / 3$ patients were properly prescribed the recommended yearly influenza vaccination at our center 2) only $1 / 4$ were vaccinated and most of their parents were misinformed. Physicians must be aware of this and should make every effort to better inform their patients on the risks of flu illness and the benefits and safety of the vaccination.

Keywords: Influenza, Vaccination, Idiopathic nephrotic syndrome, Practices, Efficacy, Safety

\section{Background}

Idiopathic nephrotic syndrome (INS) is the most prevalent glomerular disease in children with an incidence ranging from 1 to $4 / 100.000$ children/year [1]. It is characterized by massive proteinuria and hypoalbuminemia. An immunological origin has long been postulated, although the precise mechanisms underlying the disease

\footnotetext{
* Correspondence: klifaroman@msn.com

${ }^{1}$ Néphrologie Pédiatrique, Centre de Référence du Syndrome Néphrotique Idiopathique de l'enfant et l'adulte, Assistance Publique-Hôpitaux de Paris, Hôpital Necker-Enfants Malades, Université Paris Descartes, Sorbonne paris Cité, 149 rue de Sèvres, 75015 Paris, France

Full list of author information is available at the end of the article
}

remain under debate. Many of these children subsequently relapse and require long-term steroid therapy and/or steroid-sparing agents. Immunogenic stimuli such as viral infections or vaccine shots have been incriminated for triggering off relapses [2, 3]. On the contrary some viral infections like measles may induce long-lasting remissions [4].

The flu is a common contagious disease caused by primary influenza A or B infection. Worldwide, annual epidemics result in approximately 1 billion cases of influenza, in about three to 5 million cases of severe illness, and in about 250,000 to 500,000 deaths [5]. In

(c) The Author(s). 2019 Open Access This article is distributed under the terms of the Creative Commons Attribution 4.0 International License (http://creativecommons.org/licenses/by/4.0/), which permits unrestricted use, distribution, and reproduction in any medium, provided you give appropriate credit to the original author(s) and the source, provide a link to the Creative Commons license, and indicate if changes were made. The Creative Commons Public Domain Dedication waiver (http://creativecommons.org/publicdomain/zero/1.0/) applies to the data made available in this article, unless otherwise stated. 
2016-2017's winter the number of consultations for influenza-like illness during the epidemic was estimated to 2.3 millions in France in which the proportion of patients under 15 years of age was $42 \%$, the highest rate since 2011 [6].

In healthy children, the systemic symptoms are usually moderate and serious complications are unusual. Symptoms typically include the sudden onset of lasting high fever, cough and muscle aches. Other common symptoms include headache, chills, loss of appetite, fatigue and sore throat. Nausea, vomiting and diarrhea may also occur, especially in children. Most people will recover within a week or 10 days, but some are at greater risk of more severe complications, including pneumonia, encephalitis, myocarditis, and death [7]. Indeed, the highest risk of complications occurs among pregnant women, children aged from 6 to 59 months, people above 65 years, patients with chronic disease (including kidney diseases) or receiving immunosuppressive treatment, and obese subjects [5].

To prevent flu disease and its complications, the World Health Organisation recommends vaccination for at-risk groups such as children from 6 months to 5 years or individuals with chronic medical conditions [5]. In France, the High Council for Public Health (HCSP) recommends annual influenza vaccination in all children with INS. To this end, the French Health insurance sends yearly, as soon as the vaccine has been released, a flu-vaccine prescription to the patients' homes. The aim of this study was to evaluate the follow-up to these recommendations.

\section{Methods}

We conducted a monocentric retrospective investigation of practices on children followed in the pediatric nephrology unit at Necker Children's Hospital, Paris, France. We included all consecutive children (1-18 years) with steroid-sensitive INS in remission for at least 3 months, who attended our pediatric nephrology clinics for the past 2 years, who resided in France, and had a valid phone number. Steroid-sensitive INS was defined by achievement of complete remission (negative proteinuria on 2 consecutive days) within 1 month of daily prednisone therapy at $60 \mathrm{mg} / \mathrm{m}^{2} \pm 3$ methylprednisolone pulses [8]. Data were collected from May 2017 to June 2017 for the 2016-2017's flu season through a phone interview of the patient's parents/legal guardians (Additional file 1) and data were gathered from patients' chart. A single operator who did not know the patients and their families collected the data. Patients who could not be reached by phone or did not agree to participate were excluded from the study. In this retrospective survey, the flu was defined only by the symptoms of influenza-like illness (ILI) (i.e., temperature $\geq 38^{\circ} \mathrm{C}$ for several days, chills, muscle aches and either cough or sore throat). The relapse was defined by (i) a proteinuria $\geq 3+$, for three consecutive days and (ii) the need for intensified steroid therapy. Transient proteinuria was not considered as a relapse.

During the 2016-2017's flu season, the available vaccine in France was an intramuscular inactivated trivalent vaccine with 2 viral strains of influenza type $A(H 1 N 1$ and H3N2) and 1 viral strain of influenza type B. For the pediatric population, the vaccination strategy depends on the age. Between six to 35-month-old children: 2 half dose $(0.25 \mathrm{ml})$ of vaccine are given for primary immunization and only 1 half dose for booster. Between three to eight-year-old children: 2 doses $(0.5 \mathrm{ml})$ within a month are administered for primary immunization and 1 dose for booster. Above 9-year-old children only one dose is given. Each dose was given by intramuscular injection. Each season the vaccination campaign begins in October and ends in January.

The study was approved by the local institutional review board, declared to the Information Technology and Liberty Commission (CNIL \# $2105091 \mathrm{v0}$ ) and conducted in accordance with the declaration of Helsinski.

Analyses were performed using Prism software (GraphPad Software). Results are expressed as mean \pm SD or median (range). Continuous data were tested for normal distribution using Kolmogorov-Smirnov test. Normally distributed data were analysed with the Student $t$ test. Non-parametric data were analysed with the Mann-Whitney U test. Frequencies and contingency tables were analysed using the Fisher's exact two-tailed test. Statistical significance was set at $p<0.05$.

\section{Results}

Eighty-one patients followed for INS in the past 2 years were identified. Seventy-five met the inclusion criteria. Fifty-seven parents/legal guardians could be reached by phone; all of them agreed to participate and were included in the study (Fig. 1). The characteristics of the patients are reported in Table 1 . The median age at inclusion was 12.8 years and the sex ratio $(\mathrm{M} / \mathrm{F})$ was $3: 1$.

Twenty-seven families (47.4\%) were not aware of the recommendations before this survey. Eighteen children $(31.5 \%)$ had been vaccinated annually against the flu in the years preceding the study.

Thirty-five parents (61.4\%) declared having received a prescription from the French Social Security or from their physician during the 2016-2017 flu season. Fourteen patients in total $(24.6 \%)$ and $37 \%$ of those who had received the vaccine prescription were vaccinated during the campaign, all with an inactivated vaccine (intramuscular injection).

The clinical characteristics did not statistically differ among children who did or did not receive the vaccine (Table 1). 


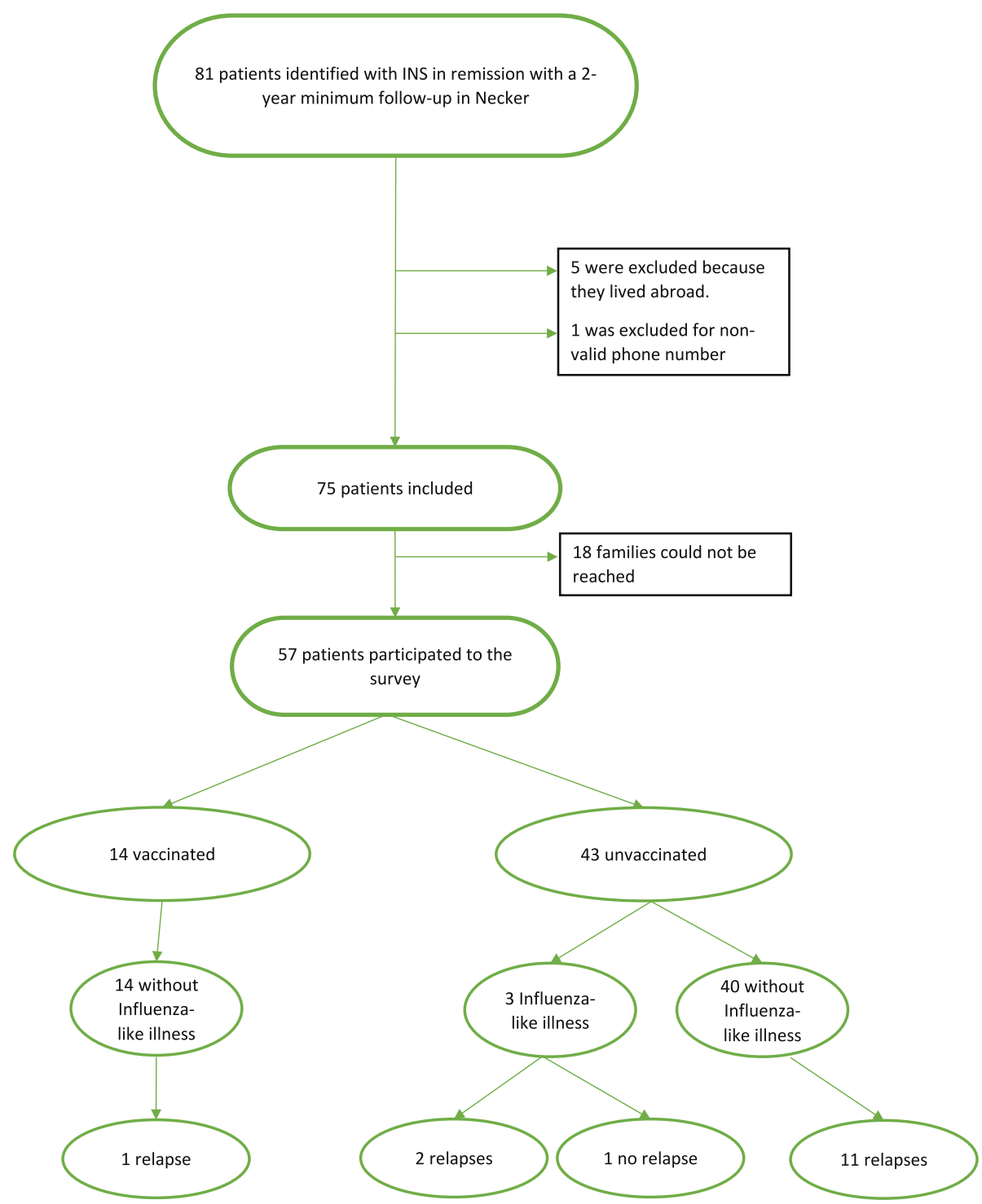

Fig. 1 Flow chart

Among the 43 parents of unvaccinated children, 17 (39.5\%) had concerns about the vaccine's safety, 16 (37.2\%) were not aware of the recommendations, 5 (11.6\%) had been told by their physician (general practitioner, pediatrician or nephrologist) not to immunize their child, 3 (7\%) had forgotten to have their child vaccinated before the end of the flu season, 2 (4.6\%) reported no reason for non-vaccination.

Among the 43 unvaccinated patients, three (7\%) presented an influenza-like illness (Fig. 1). Two of them experienced INS relapse a few days after the beginning of the symptoms. In addition, 11/43 patients presented a relapse during the following 6-month flu season period. Thus, in total, 13/43 (25.5\%) unvaccinated patients presented a relapse during the flu season period. Relapse rates were not significantly different between patients without influenza-like illness $(n=13 / 54)$ and with influenzalike illness $(n=2 / 3, p=0.16)$.

Conversely, none of the 14 immunized children presented any influenza-like illness and only one (7\%) relapsed 15 days following vaccination. Another child presented transient proteinuria 5 months following vaccination. The relapse rate did not significantly differ between vaccinated and unvaccinated children $(p=0.15)$. Moreover, the relapse rate of vaccinated children did not differ between the 6 months preceding and the 6 months following vaccination $(5 / 14$ vs $1 / 14, p=0.20)$. The same result was observed in the unvaccinated group during the corresponding 6-month period (13/43 vs $13 / 43, p=1)$.

At the end of the phone questionnaire, the parents were informed of the recommendations and 31 (54\%) parents declared considering having their child vaccinated against 
Table 1 Patients' clinical characteristics

\begin{tabular}{|c|c|c|c|c|}
\hline Patients' characteristics & Total $N=57$ & $\begin{array}{l}\text { Vaccinated } \\
N=14\end{array}$ & $\begin{array}{l}\text { Nonvaccinated } \\
N=43\end{array}$ & $P$ value \\
\hline \multicolumn{5}{|l|}{ Age (years) } \\
\hline Median [range] & $12.8[5-18]$ & 13.3 [6-19] & $12.4[6-18]$ & 0.46 \\
\hline \multicolumn{5}{|l|}{ Gender } \\
\hline Boys (\%) & $39(70)$ & $11(78)$ & $28(65)$ & \multirow[t]{2}{*}{0.51} \\
\hline Girls (\%) & $18(30)$ & $3(22)$ & $15(35)$ & \\
\hline \multicolumn{5}{|l|}{ Age at the time of diagnosis (years) } \\
\hline Median [range] & $3.3[1-7]$ & $3[1-6]$ & $3.4[1-7]$ & 0.60 \\
\hline \multicolumn{5}{|l|}{ Duration of illness (years) } \\
\hline Median [range] & $9.05[3-16]$ & 9.78 [3-16] & $8.72[3-16]$ & 0.12 \\
\hline Current immunosuppressive treatment & $42(74)$ & $11(78)$ & $31(72)$ & 0.73 \\
\hline Prednisone & 9 & 1 & 8 & 0.43 \\
\hline Prednisone + tacrolimus & 1 & 0 & 1 & 0.22 \\
\hline Prednisone + mycophenolate & 15 & 6 & 9 & 1 \\
\hline Prednisone + ciclosporine & 3 & 1 & 2 & 1 \\
\hline Prednisone + levamisole & 2 & 0 & 2 & 1 \\
\hline Prednisone + tacrolimus + mycophenolate & 5 & 1 & 4 & 1 \\
\hline Rituximab & 1 & 1 & 0 & 0.25 \\
\hline Mycophenolate & 6 & 1 & 5 & 1 \\
\hline No Treatment & $15(26)$ & $3(22)$ & $12(28)$ & 0.89 \\
\hline \multicolumn{5}{|l|}{ Relapses } \\
\hline During the six months prior to vaccination and/or flu season & $18(31)$ & $5(36)$ & $13(30)$ & 0.74 \\
\hline During the six months following vaccination and/or during flu season & $15(26)$ & $1(7)$ & $13(30)$ & 0.31 \\
\hline
\end{tabular}

the flu in the following year in any case, 13 (23\%) others stated they would have their child vaccinated as long as their general practitioner/pediatrician would recommend it as well. The last 13 parents (23\%) stated that they would still refuse to vaccinate their children for the next seasons.

\section{Discussion}

This study shows that only a quarter of patients followed for INS at our institution were vaccinated against the flu during the 2016-2017 season, whereas at least $77 \%$ of the families would consider having their child vaccinated if their physicians recommended it for the next flu seasons. Among the parents of unvaccinated children, 39\% had concerns about the safety of the vaccine, some of whom because of their physicians' recommendations, but most of them because of a lack of information.

However, these results must be treated carefully. Indeed, the retrospective nature of this study may have biased the data. In this retrospective survey, the diagnosis of influenza-like illness was based on signs and symptoms, as recommended for outpatients. Therefore, some of these influenza-like illnesses may be caused by another virus. The Center for Disease Control (CDC) reported only $54.6 \%$ PCR positivity among US patients diagnosed with influenza-like illnesses during the 20172018's winter [9].

In the present study, 2 out of the 3 INS patients with an influenza-like illness relapsed a few days later. In children with INS, viral infections may trigger off a relapse or may be severe with potential pneumococcal infection [10]. Therefore, influenza vaccination has been recommended for children with INS by the French High Council of Public Health since 2000. Larger indications exist around the world: in the United Kingdom, a yearly influenza vaccination is recommended for all children between 2 and 9 years of age [11]. In the USA, the CDC recommends yearly influenza vaccination for every person aged 6 months or more [12]. For the 2016-2017's season the CDC has recommended to use only the inactivated vaccine, the only one available in France this season, due to the lack of efficiency of the live attenuated one [13]. In Canada, influenza vaccination is recommended for all individuals aged 6 months and older [14].

A decline in vaccination trust has impaired vaccination programs this last decade. Such decline is illustrated by the so-called revival of antivaccination movements [15-17]. The high rate of flu vaccine mistrust observed in our study is in line with the general vaccine mistrust in France, a 
country with historical difficulties regarding mistrusts towards vaccination $[18,19]$. We showed that, despite the recommendations, $39.5 \%$ of the parents of non-vaccinated children did not trust the safety of the vaccine and that only one fourth of the patients of the present study were vaccinated against the flu. For the 2016-2017 season, the vaccination rate of the population targeted by the recommendations was $46 \%$ which is 1.84 times higher than the vaccinal coverage of our INS patients [20].

As mentioned above, the main reason for non-vaccination in the present study was vaccine mistrust, followed by a lack of information and, in some cases, a recommendation from their physician (general practitioner, pediatrician or nephrologist). This is consistent with the literature, in which the main reason for this opposition is also vaccine mistrust. There are also heterogeneous vaccination practices among physicians. Indeed Pulcini et al. showed that the personality of the general practitioner may be decisive on vaccination behaviour [21] Some physicians recommended not to immunize some of the patients. We did not know if this was because of an acute event such as an infection at the time of appointment or if it was for fear of relapses. Nevertheless, it remains crucial to insist on the importance of influenza vaccination among our patients.

The effectiveness of influenza vaccination can vary considerably from year to year due to the viral strains, or the immunization programs [22-25]. For the 20162017's season, according to the CDC's data, the overall vaccine effectiveness was $42 \%$. More precisely the effectiveness was $61 \%$ among the patients between 6 months to 8 years of age, and $35 \%$ between 9 to 17 years of age [26]. Recently Flannery et al. published the first study using laboratory-confirmed outcomes to investigate influenza vaccine effectiveness [27]. They showed an estimated influenza vaccine effectiveness of $65 \%$ (95\% CI, 54 to $74 \%$ ) against laboratory-confirmed influenza-associated deaths among children. This effectiveness was lower in children with underlying medical conditions 51\% (95\% CI, 31 to $67 \%$ ), but protection remained significant.

Data on influenza vaccine efficacy in INS are scarce. In their study in 1979, Sheth et al. showed for the first time that INS patients could be effectively immunized against influenza. 83\% (25/30) of their patients with renal disease (predominantly INS) had a sufficient antibody titer 1 year after vaccination that was similar to the control group. Poyrazoglu et al. showed an adequate IgG titer 1 and 6 months after influenza A immunization in 19 children with INS [28].

Serological efficacy in INS has also been reported in small series with other vaccines such as VZV-vaccine which induces a lasting antibody response with titers comparable to those of healthy control 2 years later [28, 29]. Ulinski et al. demonstrated a good serological response to the 23-pneumococcal vaccine on high-dose steroids in 43 with INS in remission or in relapse [10] This was subsequently demonstrated with the 13-valent pneumococcal conjugate [30] and is consistent with another series of 29 children with INS who developed adequate antibody titers after booster immunization with 7-valent pneumococcal conjugate vaccine [31]. However, there are no available data on long-term clinical efficacy.

In the present study, patients' parents/legal guardians reported no flu-like illness in the vaccinated group. However, these results are to be taken with caution since this study was not designed to evaluate the efficacy of influenza vaccination or vaccine-induced disease.

Older publications and a few case reports support the idea that immunizations through vaccination may cause, exacerbate or precipitate relapses in INS. In their study in 1979, Sheth et al. showed that one patient had a minor post-vaccination cold illness and relapsed within days after vaccination [32].

In 2003 Abeyagunawardena et al. reported patients with INS among whom $45.7 \%$ had relapses "attributable to vaccination" against the Meningococcal $\mathrm{C}$ vaccine [33]. This study may be biased due to its retrospective nature. Moreover, it compared the relapse rate in the year preceding vaccination to that of the year following vaccination, although vaccine-induced relapses are expected to occur in the first few weeks following administration. In another small heterogeneous series of 41 children not designed to study the effect of vaccination on NS relapses, Yildiz et al. observed an increased relapse rate from $0.12 \pm 0.19$ to $0.4 \pm 0.12$ relapse/month in the month following hepatitis $\mathrm{B}$ vaccination $(p=0.002)$ [34]. However, the authors recommend vaccinating children with INS against hepatitis B in endemic regions.

Conversely, all the subsequent publications reported that the vaccination with the VZV, influenza or pneumococcal vaccines seems safe in patients with INS without any significant increase of relapses [29, 31, 35]. For instance, Taylor et al. did not observe any increased risk of relapse of INS after vaccination against Meningococcal $\mathrm{C}$ in a cohort of 54 patients [35]. Our study is in accordance with this growing body of evidence regarding the safety of the vaccine (Additional file 2) [28, 29, 31, 35]. Indeed, we did not observe an increased risk of vaccine-induced relapse of INS (1/14 (7\%) relapses in the 6 months after vaccination versus $5 / 14(36 \%)$ in the 6 months before vaccination $p=0.20$ ), even though our study was not designed to evaluate the safety of vaccination and the risk of vaccine-induced relapse.

The relapse rate in children who did not present an influenza-like illness seems increased in patients who did not receive the vaccine $11 / 40$ (28\%) compared to vaccinated children $1 / 14(7 \%)$, but the difference is not significant $(p=0.15)$. We do not believe that vaccination 
has a flu-independent protective effect on the relapserisk. This trend may due to a selection bias. Moreover, the parental mistrust in vaccination may be associated to a poorer adhesion to other NS treatments in the group of unvaccinated children.

Moreover, there was no significant side effect of the vaccines in the above-mentioned publications. The only concern is with the live vaccines like the VZV or measles for which a steroid therapy less or equal to $2 \mathrm{mg} / \mathrm{kg} /$ day is recommended for safety and efficacy $[29,36]$. In the present survey, no vaccinated child presented any vaccine-induced influenza-like illness and parents reported no significant side effect.

\section{Conclusion}

This practice survey shows that fewer than $2 / 3$ patients are properly prescribed the recommended yearly influenza vaccination at our center. Only $1 / 4$ of the patients were vaccinated and most of their parents were misinformed. Relapse rates were not increased in vaccinated children compared to unvaccinated children $(p=0.15)$, nor in the 6 months following vaccination compared to the 6 months prior $(1 / 14$ vs $5 / 14, p=0.20)$.

Pediatric nephrologists and all physicians following INS patients must be aware of this and should make every effort to better inform their patients and parents of the risks of flu illness and of the benefits and safety of the vaccination. To improve practices, we intend, from now on, to send a personal letter of information to each INS patient's family during the vaccination campaign along with a prescription to reinforce oral recommendations provided during the consultations and Public Health vaccination programs. Besides, recently, 11 vaccines became mandatory in the vaccinal schedule in France. Such a change could probably help to modify French population mistrust of vaccines.

\section{Additional files}

Additional file 1: Table S1. Patient questionnaire. (DOCX $70 \mathrm{~kb}$ )

Additional file 2: Table S2. Review of the literature: ("Nephrotic Syndrome"[Mesh]) AND "Vaccines"[Mesh] AND "Child"[Mesh], limited to 15 years with exclusion of articles written in other languages than English. (DOCX 103 kb)

\section{Abbreviations}

CDC: Center for disease control; HCSP: High Council for Public Health; INS: Idiopathic nephrotic syndrome

\section{Acknowledgments}

We sincerely thank Nicolas Garcelon from Data Science Platform, Institut Imagine, Université Paris Descartes, Sorbonne Paris Cité, Paris, France.

\section{Availability of data and materials}

The datasets used and/or analysed during the current study are available from the corresponding author on reasonable request.

Transparency declarations

All authors declare having no conflict of interest.

\section{Authors' contributions}

R.K conceptualized and designed the study, coordinated data collection, conducted the initial analyses, interpreted the data and drafted the initial manuscript. J.T and O.B conceptualized and designed the study, coordinated and supervised data collection, interpreted the data and critically reviewed and revised the manuscript. A.M, N.B, M.C, P.K, L.H, S.K and R.S participated to acquisition of data collection and critically reviewed and revised the manuscript.

All authors approved the final manuscript as submitted and agree to be accountable for all aspects of the work.

Ethics approval and consent to participate

Ethics committee of Necker-Enfants Malades (which belongs to Necker-Enfants Malades Hospital) ruled that no formal ethics approval was required in this aparticular case. The consent from study participants was verbal and was approved by the local ethic committee.

\section{Consent for publication}

Not applicable

\section{Competing interests}

The authors declare that they have no competing interests.

\section{Publisher's Note}

Springer Nature remains neutral with regard to jurisdictional claims in published maps and institutional affiliations.

\section{Author details}

${ }^{1}$ Néphrologie Pédiatrique, Centre de Référence du Syndrome Néphrotique Idiopathique de l'enfant et l'adulte, Assistance Publique-Hôpitaux de Paris, Hôpital Necker-Enfants Malades, Université Paris Descartes, Sorbonne paris Cité, 149 rue de Sèvres, 75015 Paris, France. ²Pédiatrie Générale et Infectieuse, Assistance Publique-Hôpitaux de Paris, Hôpital Necker-Enfants Malades, Université Paris Descartes, Sorbonne paris Cité, Paris, France.

Received: 20 September 2018 Accepted: 30 January 2019

Published online: 25 February 2019

\section{References}

1. Dossier C, Lapidus N, Bayer F, et al. Epidemiology of idiopathic nephrotic syndrome in children: endemic or epidemic? Pediatr Nephrol Berl Ger. 2016; 31:2299-308.

2. Grupe WE. Childhood nephrotic syndrome: clinical associations and response to therapy. Postgrad Med. 1979;65:229-36.

3. Schnaper HW. The immune system in minimal change nephrotic syndrome. Pediatr Nephrol. 1989;3:101-10.

4. Lin C-Y, Hsu H-C. Histopathological and immunological studies in spontaneous remission of nephrotic syndrome after Intercurrent measles infection. Nephron. 1986:42:110-5.

5. Anon. WHO | Influenza (Seasonal). WHO. Available at: https://www.who.int/ en/news-room/fact-sheets/detail/influenza-(seasonal). Accessed 10 Oct 2017.

6. Équipes de surveillance de la grippe. Surveillance de la grippe en France métropolitaine, saison 2015-2016. Bull Epidémiol Hebd. 2016;(32-33):558-63. http://invs.santepubliquefrance.fr/beh/2016/32-33/2016_32-33_1.html.

7. Bhat N, Wright JG, Broder KR, et al. Influenza-associated deaths among children in the United States, 2003-2004. N Engl J Med. 2005:353:2559-67.

8. Avner ED, Harmon WE, Niaudet P, Yoshikawa N, Emma F, Goldstein SL. Idiopathic Nephrotic Syndrome in Children: Clinical Aspects. In: Niaudet P, Boyer O, editors. Pediatric Nephrology. 7th ed. Berlin Heidelberg: SpringerVerlag; 2016. Available at: //www.springer.com/in/book/9783662435953.

9. Garten R. Update: influenza activity in the United States during the 2017-18 season and composition of the 2018-19 influenza vaccine. MMWR Morb Mortal Wkly Rep. 2018;67. Available at: https://www.cdc.gov/mmwr/ volumes/67/wr/mm6722a4.htm Accessed Dec 19, 2018.
Funding

Not applicable. 
10. Ulinski T, Leroy S, Dubrel M, Danon S, Bensman A. High serological response to pneumococcal vaccine in nephrotic children at disease onset on high-dose prednisone. Pediatr Nephrol. 2008;23:1107-13.

11. Choices NHS. Children's flu vaccine - vaccinations - NHS Choices 2017. Available at: http://www.nhs.uk/Conditions/vaccinations/Pages/child-fluvaccine.aspx. Accessed Oct 10, 2017.

12. Fiore $A E$, Shay DK, Broder $K$, et al. Prevention and control of influenza: recommendations of the advisory committee on immunization practices (ACIP), 2008. MMWR Recomm Rep Morb Mortal Wkly Rep Recomm Rep. 2008:57:1-60.

13. Jackson ML, Chung JR, Jackson LA, et al. Influenza vaccine effectiveness in the United States during the 2015-2016 season. N Engl J Med. 2017;377: 534-43.

14. Canada PHA of, Canada PHA of. Canadian Immunization Guide Chapter on Influenza and Statement on Seasonal Influenza Vaccine for 2016-2017. gcnws 2016. Available at: https://www.canada.ca/en/public-health/services/ immunization/national-advisory-committee-on-immunization-naci/canadianimmunization-guide-chapter-on-influenza-statement-on-seasonal-influenzavaccine-2016-2017-advisory-committee-statement.html. Accessed Oct 26, 2017.

15. Gangarosa EJ, Galazka AM, Wolfe CR, et al. Impact of anti-vaccine movements on pertussis control: the untold story. Lancet Lond Engl. 1998;351:356-61.

16. Wolfe RM, Sharp LK, Lipsky MS. Content and design attributes of Antivaccination web sites. JAMA. 2002;287:3245-8.

17. Poland GA, Jacobson RM. The age-old struggle against the Antivaccinationists. N Engl J Med. 2011;364:97-9.

18. Peretti-Watel $P$, Verger $P$, Raude J, et al. Dramatic change in public attitudes towards vaccination during the 2009 influenza a (H1N1) pandemic in France. Eurosurveillance. 2013;18:20623.

19. Larson HJ, de Figueiredo A, Xiahong Z, et al. The state of vaccine confidence 2016: global insights through a 67-country survey. EBioMedicine. 2016;12:295-301.

20. Anon. Article - Bulletin épidémiologique hebdomadaire. Available at: http:// invs.santepubliquefrance.fr/beh/2017/22/2017_22_1.html. Accessed Mar 10, 2018.

21. Massin S, Ventelou B, Nebout A, Verger P, Pulcini C. Cross-sectional survey: risk-averse French general practitioners are more favorable toward influenza vaccination. Vaccine. 2015;33:610-4.

22. Belongia EA, Kieke BA, Donahue JG, et al. Effectiveness of inactivated influenza vaccines varied substantially with antigenic match from the 2004-2005 season to the 2006-2007 season. J Infect Dis. 2009:199:159-67.

23. DiazGranados CA, Dunning AJ, Kimmel M, et al. Efficacy of high-dose versus standard-dose influenza vaccine in older adults. N Engl J Med. 2014;371: 635-45.

24. Jackson $M L$, Jackson $L A$, Kieke $B$, et al. Incidence of medically attended influenza infection and cases averted by vaccination, 2011/12 and 2012/13 influenza seasons. Vaccine. 2015;33:5181-7.

25. McLean $\mathrm{HQ}$, Thompson MG, Sundaram ME, et al. Influenza vaccine effectiveness in the United States during 2012-2013: variable protection by age and virus type. J Infect Dis. 2015:211:1529-40.

26. Anon. flu-03-ferdinands.pdf. Available at: https://www.cdc.gov/vaccines/ acip/meetings/downloads/slides-2017-06/flu-03-ferdinands.pdf. Accessed Mar 13, 2018.

27. Flannery B, Reynolds SB, Blanton L, et al. Influenza vaccine effectiveness against pediatric deaths: 2010-2014. Pediatrics. 2017;139:e20164244.

28. Poyrazoglu HM, Düsünsel R, Gündüz Z, Patiroglu T, Köklü S. Antibody response to influenza a vaccination in children with nephrotic syndrome. Pediatr Nephrol. 2004;19:57-60.

29. Alpay H, Yıldız N, Onar A, Temizer H, Özçay S. Varicella vaccination in children with steroid-sensitive nephrotic syndrome. Pediatr Nephrol. 2002;17:181-3.

30. Pittet LF, Posfay-Barbe KM, Chehade $\mathrm{H}$, et al. Optimizing seroprotection against pneumococcus in children with nephrotic syndrome using the 13valent pneumococcal conjugate vaccine. Vaccine. 2016;34:4948-54.

31. Liakou CD, Askiti V, Mitsioni A, Stefanidis CJ, Theodoridou MC, Spoulou VI. Safety and immunogenicity of booster immunization with 7-valent pneumococcal conjugate vaccine in children with idiopathic nephrotic syndrome. Vaccine. 2014;32:1394-7.

32. Sheth KJ, Sedmak GV, Freeman ME, Eisenberg C. HemagglutinationInhibiting antibodies in vaccinated children with renal disease. JAMA. 1979:242:1752-4.
33. Abeyagunawardena AS, Goldblatt D, Andrews N, Trompeter RS. Risk of relapse after meningococcal $C$ conjugate vaccine in nephrotic syndrome. Lancet Lond Engl. 2003;362:449-50.

34. Yıldız N, Sever L, Kasapçopur ö, Çullu F, Arısoy N, Çalışkan S. Hepatitis B virus vaccination in children with steroid sensitive nephrotic syndrome: immunogenicity and safety? Vaccine. 2013;31:3309-12.

35. Taylor B, Andrews N, Stowe J, Hamidi-Manesh L, Miller E. No increased risk of relapse after meningococcal C conjugate vaccine in nephrotic syndrome. Arch Dis Child. 2007:92:887-9.

36. Kamei K, Miyairi I, Ishikura K, et al. Prospective study of live attenuated vaccines for patients with nephrotic syndrome receiving immunosuppressive agents. J Pediatr. 2018. Available at: http://linkinghub. elsevier.com/retrieve/pii/S0022347617317560; Accessed Mar 24, 2018.
Ready to submit your research? Choose BMC and benefit from:

- fast, convenient online submission

- thorough peer review by experienced researchers in your field

- rapid publication on acceptance

- support for research data, including large and complex data types

- gold Open Access which fosters wider collaboration and increased citations

- maximum visibility for your research: over $100 \mathrm{M}$ website views per year

At $\mathrm{BMC}$, research is always in progress.

Learn more biomedcentral.com/submissions 